\title{
Residency cuts reveal workforce plan flaws
}

$\mathrm{C}$ anadian medical students will have to wait until September to find out the details of new cuts to Ontario residency placements. But given the patchwork management of Canada's physician supply, experts say it may be impossible to know the cuts' full impact.

"The prediction of exactly how many physicians we need is a difficult formula, and the reality is we haven't had comprehensive efforts at manpower planning that cross the boundaries of our provinces," says Dr. Richard Reznick, dean of the Faculty of Health Sciences at Queen's University in Kingston, Ontario.

In July, the province announced it was eliminating 25 residency positions in 2016 and another 25 in 2017.

Deans of Ontario medical schools are currently negotiating the distribution of reductions, which will be based on the proportion of residency positions at each school. For example, Western University in London, Ontario, expects to lose four positions.

Shae Greenfield, a spokesperson for Ontario's health minister, says only the Northern Ontario School of Medicine will be exempt from cuts. "We know that we need more physicians in the North."

Beyond this, the rationale for the cuts remains hazy. Greenfield alludes to a surplus of doctors: "After a decade of growth, it is prudent ... to ensure that we have the right mix and number."

He also notes that Ontario's physician workforce is expected to grow by $13 \%$ by 2021 - almost triple the province's population growth.

Still, the Ontario Medical Association (OMA) calls the cuts "irresponsible" at a time when 800000 Ontarians lack a family doctor. "We believe this move is based purely on fiscal considerations and not the health care needs of Ontarians," stated OMA President Dr. Mike Toth.

Reznick says it's difficult to assess what those needs might be in the absence of "robust medical manpower statistics" at the national level. "Ontario is making decisions based on local data ... drawing inferences from a minority of specialties where there appears to be a very small percentage of physicians struggling to find positions."

According to a Royal College of

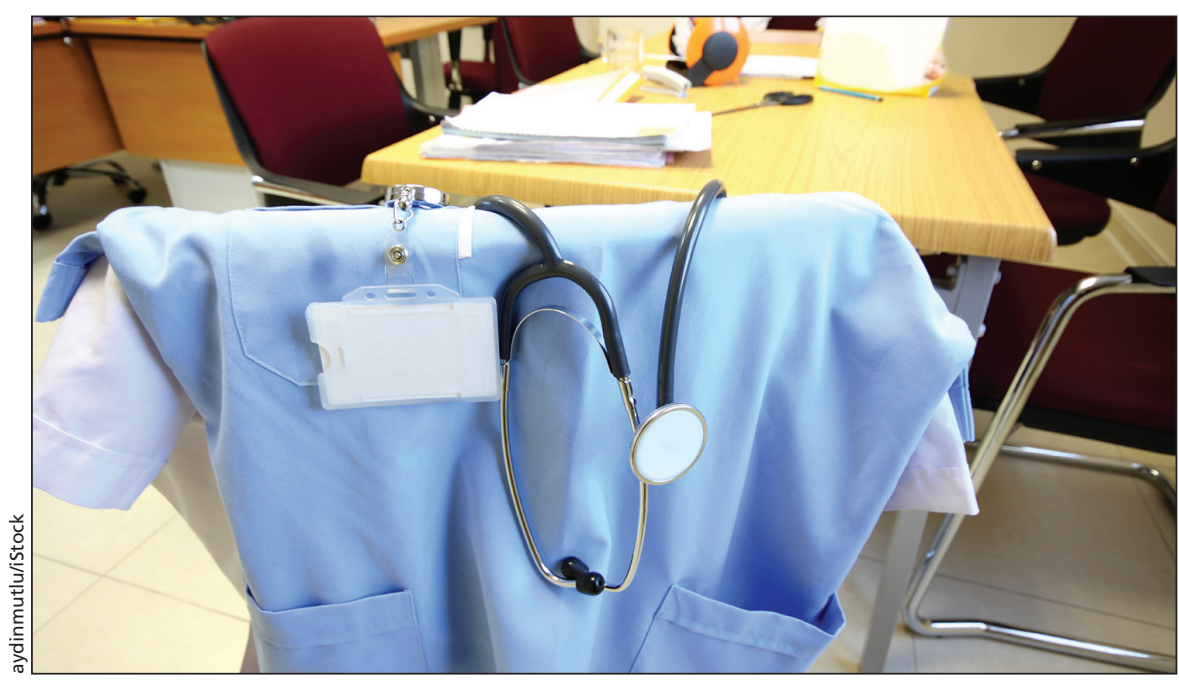

The long-term ramifications of Ontario's plan to slash 50 residency positions are unknown.

Physicians and Surgeons of Canada data, about $14 \%-17 \%$ of Canadian physicians had problems finding employment in the last three years.

But it's naive to assume that physician unemployment means an oversupply, says Danielle Fréchette, executive director for health systems innovation and external relations at the college.

She cites unemployment among orthopedic surgeons as an example. Although there's high demand for these specialists, provinces have "failed to match the practice resources with the production of physicians." Cuts to residency positions won't address population needs or the cause of unemployment in this case, "because surgeons need operating rooms and hospital beds," she says.

Given the lack of national data on the physician supply, Reznick argues that "it's not reasonable to think that we can get this at $100 \%$ accuracy ... if we do, we get perilously close to a line where Canadians don't have enough physicians to look after them."

A "very nascent committee" composed of deputy ministers and the Association of Faculties of Medicine of Canada will be looking at the problem, says Reznick. However, “there's really nothing that approaches a contemporary consensus on medical manpower in Canada."

\section{Students face a tougher match}

The news of the cuts comes late in the game for graduating medical students, who started the 2016 application process on Sept. 2.

"Students start planning their path to a specialty years in advance and pick electives based on where they want to match," says Justin Cottrell, director of representation for the Ontario Medical Students Association. "A lot of those electives have already been decided."

In the face of a more competitive match, many students are applying more broadly, including elsewhere in Canada and internationally, says Dr. Melanie Bechard, vice-president of government affairs for the Canadian Federation of Medical Students.

"We have seen applicants who have gone unmatched after two years," she says. "At that point it's really difficult to go through the match process again."

Eighty-five Canadian medical graduates didn't match to a residency position in 2015, compared to just seven in 2005.

Greenfield says there will still be more residency spaces after the cuts than the number of medical students graduating in Ontario.

But Bechard says that doesn't account for competition from graduates outside the province or those who didn't match in previous years. "To say there are enough spots really discounts an enormous proportion of applicants." — Lauren Vogel, CMAJ

CMAJ 2015. DOI:10.1503/cmaj.109-5130 